\title{
Cross-transfer of motor control in visuomotor tasks. Systematic review
}

\author{
Javier Ruiz-Seijoso', Yaiza Taboada-Iglesias² \\ ${ }^{\prime}$ Facultad de Fisioterapia. Universidade de Vigo, Pontevedra. ${ }^{2}$ Facultad de Fisioterapia. Departamento de Biología Funcional y Ciencias de la Salud. Universidade de Vigo, Pontevedra, \\ España. GIES-10(DE-3), Instituto de Investigación Sanitaria Galicia Sur (IIS Galicia Sur), SERGAS-UVIGO).
}

doi: 10.18176/archmeddeporte.00063

Received: 09/11/2020

Accepted: 11/06/2021

Key words:

Cross-transfer. Cross-education. Interlimb-transfer. Crossover effect. Motor control. Ability. Visuomotor.

\section{Summary}

Introduction: The term "cross-education" describes the perfomance improvement, both in motor control and strength, of a limb after training the opposite. Despite its current interest, there is no consensus on many concepts of the transfer of a visuomotor skill. The aim of the present research was to review the current literature on the phenomenon of cross-education in visuomotor skills in order to determine the magnitude of transference and its relationships with the context of the intervention. Results: A literature search was conducted during December 2019 in the databases Pubmed, CINAHL, MEDLINE, Web of Science, SPORTdiscus and Scopus. The descriptors "Motor ability" and "Motor skill" were used, in addition to the keywords

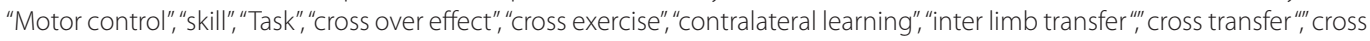
education". After applying the inclusion and exclusion criteria, a total of 19 articles were obtained for analysis. Of these articles, 12 are RCTs, 4 crossover clinical trial, 2 are non-randomized trials and only 1 lacks a control group. Most of the articles consist of a short-term intervention. Only 5 studies are of a duration of between 4 and 6 weeks.

Conclusion: the cross-education phenomenon occurs in visuomotor skills. However, the magnitude of transference and its relation to the amount of learning of the trained member seems to be very variable depending on the context of the intervention. Likewise, the scarce consensus and the methodological differences in the studies make it difficult to draw firm conclusions about the effects of the context on the transference.

\section{Transferencia cruzada en el control motor en tareas visuomotoras. Revisión sistemática}

\section{Resumen}

Introducción: El término cross-education describe la mejora de rendimiento, tanto en control motor como en fuerza, de un miembro tras el entrenamiento del contrario. A pesar de su actual interés, no existe consenso en muchos conceptos de la transferencia de una habilidad visuomotora.

Objetivo: El objetivo del presente estudio fue revisar la literatura actual sobre el fenómeno cross-education en habilidades visuomotoras para determinar la magnitud de transferencia y sus relaciones con el contexto de la intervención.

Resultados: Se realizó una búsqueda bibliográfica durante diciembre de 2019 en las bases de datos Pubmed, CINAHL, MEDLINE, Web of Science, SPORTdiscus y Scopus. Se emplearon los descriptores "Motor ability"y "Motor skill", además de las palabras clave "Motor control,", "skill", "Task", "cross over effect", "cross exercise," "contralateral learning", "inter limb transfer", "cross transfer", "cross education". Tras la aplicación de los criterios de inclusión y de exclusión, se obtuvo un total de 19 artículos para realizar el análisis. De estos artículos, 12 son ECA, 4 ensayos clínicos cruzados, 2 son ensayos no aleatorizados y solo 1 carece de grupo control. La mayoría de artículos constan de una intervención a corto plazo. Tan solo 5 estudios son de una duración de entre 4 y 6 semanas.

Palabras clave:

Cross-transfer. Cross-education. Interlimb-transfer. Crossover effect. Control Motor. Habilidad. Visuomotor.

Conciusión: El fenómeno cross-education ocurre en habilidades de tipo visuomotor. Sin embargo, la magnitud de transferencia y su relación con la cantidad de aprendizaje del miembro entrenado parecen muy variables dependiendo del contexto de la intervención. Asimismo, el escaso consenso y las diferencias metodológicas de los estudios dificultan extraer conclusiones contundentes acerca de los efectos del contexto sobre la transferencia. 


\section{Introduction}

The term cross-education, referred to in this review as transfer and cross-transfer, was coined by Edward Wheeler Scripture' in 1894. It defines the improvement in the performance (strength and motor control) of a limb after training the opposite counterpart, even though currently these tend to be considered two separate entities ${ }^{2,3}$.

There are two main theoretical models which justify the phenomenon: cross activation and bilateral access ${ }^{2}$. Cross activation maintains that adaptations in both cerebral hemispheres are driven by bilateral cortical activity generated during unilateral training (cross facilitation), relating the transfer of a task to the neuronal load it generates ${ }^{2}$. Bilateral access holds that motor engrams developed during unilateral training are not specific to the trained side and are accessible for both limbs ${ }^{2}$.

Aspects of cross-education are still being studied. Originally it was thought that transfer does not occur symmetrically, determining that there would only be transfer from the dominant hemisphere ${ }^{4,5}$, associating this asymmetry with hemispheric specialisation ${ }^{6}$. Another focus of attention regarding which consensus does not exist is the influence of neuronal degenerative changes. While some studies conclude that transfer is minimal in older subjects ${ }^{7,8}$, others, based on the reduction in hemispheric laterality outlined in the HAROLD model (Hemispheric Asymmetry Reduction in Older Adults $)^{9}$, point to transfer similar to that found in younger people ${ }^{10,11}$. Although many reviews analyse the scale of strength transfer and its relationship with the learning percentage of the trained limb, there are no recent reviews which reflect the magnitude of this relationship in motor control.

In recent years, the attention which the phenomenon of crosstransfer has received has increased, as has the number of trials focussing on $i^{12}$. This is due to its clinical potential and possible application in the rehabilitation of multiple conditions which involve the inability or difficulty to move a limb, be it for musculoskeletal or neurological reasons.

Given the potential of this tool and the limited consensus on it, the objective of this study is to review the current literature on cross-transfer in visuomotor skills to determine the scale of transfer and its relationships with the context of the task and the patient.

\section{Materials and methods}

\section{Search strategy}

A bibliographic search was carried out in the Pubmed, CINAHL, MEDLINE, Web of Science, SPORTdiscus and Scopus databases between 20 May and 4 June 2021, including all the studies published from 2015 to the present. The search formulas and terms were as follows:

Medline, Cinahl, Pubmed, Sportdiscus: (THESAURUS* OR "Motor skill" OR "Motor control" OR "skill" OR "Task") AND ("cross over effect" OR "cross exercise" $O R$ "contralateral learning" OR "inter limb transfer" OR "cross transfer" OR "cross education").

- Pubmed: "Motor Skills"(Mesh).
Figure 1. Study selection flow diagram.

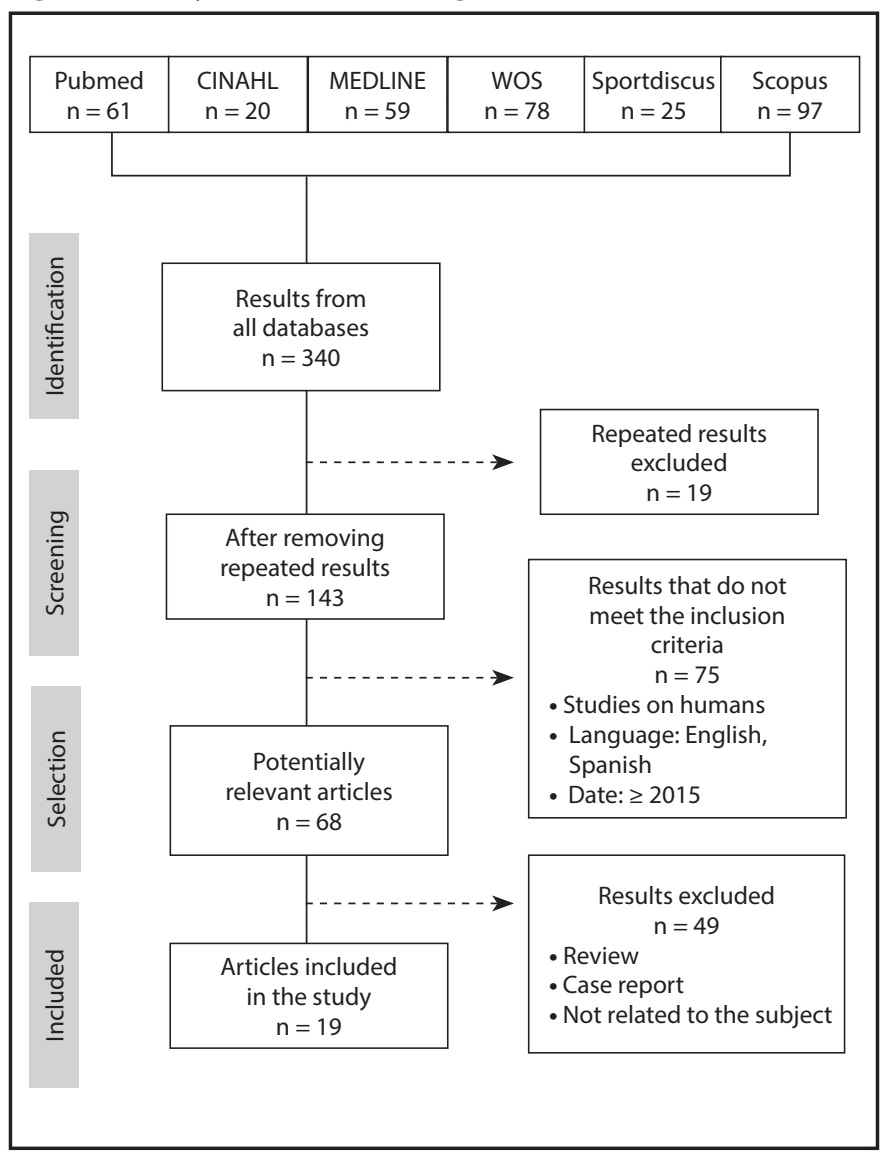

- Medline, Cinahl: MH "Motor Skills".

- Sportdiscus: DE "MOTOR ability".

- Scopus and Web of Science: TITLE-ABS-KEY (("Motor skill" OR "Motor control" OR "skill" OR "Task") AND ("cross over effect" OR "cross exercise" $O R$ "contralateral learning" OR "inter limb transfer" OR "cross transfer" $O R$ "cross education")).

To establish which results were valid for review, a set of criteria was applied following the selection process shown in Figure 1.

\section{Results}

Table 1 shows the characteristics of the papers in terms of sample, design and duration of the studies, together with an analysis of their methodological quality.

The mean of the samples is 35 individuals. Most of the studies involve young patients (22-26 years old)

All the interventions bar $8^{14,18,19,21,27-30}$ are based on tracking trajectories, points or positions. Only 5 of the studies are long-term (4-10 weeks) 3,19,27,29,30. Only 4 papers focus purely on the lower limbs ( $(L L)^{22-24,26}$ Only 5 of the studies include a washout period (1-2 weeks) 3,20,21,25. 
Table 1. Summary of the methodology of the studies analysed.

\begin{tabular}{|c|c|c|c|c|c|}
\hline & Design & Jadad & Sample & Duration & Washout period \\
\hline Leung et al. ${ }^{13}$ & $\mathrm{RCT}$ & $1 / 5$ & $\begin{array}{l}\mathrm{N}=44\left(240^{\star} \text { and } 20 \text { \% }\right) \\
\mathrm{A}=26.1 \pm 6.8 \text { years old }\end{array}$ & 2 days & 2 weeks \\
\hline Dickins et al. ${ }^{14}$ & $\mathrm{CCT}$ & $1 / 5$ & $\begin{array}{l}\mathrm{N}=40\left(200^{x} \text { and } 20 \%\right) \\
\mathrm{A}= \\
\mathrm{EG} 1: 24.25 \text { years old } \\
\mathrm{EG} 2: 70.00 \text { years old }\end{array}$ & 2 days & \\
\hline Graziado et al..$^{15}$ & NRCT & $0 / 5$ & $\begin{array}{l}\mathrm{N}=24 \\
\mathrm{~A}= \\
\mathrm{EG} 1: 28 \pm 2 \text { years old } \\
\mathrm{EG} 2: 67 \pm 9 \text { years old }\end{array}$ & 1 day & \\
\hline Pan et al. ${ }^{16}$ & $\mathrm{RCT}$ & $1 / 5$ & $\begin{array}{l}\mathrm{N}=40\left(170^{x} \text { and } 23 \%\right) \\
\mathrm{A}= \\
\mathrm{EG} 1: 71.9 \pm 9.6 \text { years old } \\
\mathrm{EG} 2: 70.4 \pm 6.8 \text { years old }\end{array}$ & 1 day & \\
\hline Sainburg et al. ${ }^{17}$ & $\mathrm{NRCT}$ & $1 / 5$ & $\begin{array}{l}\mathrm{N}=11\left(30^{\pi} \text { and } 8 \%\right) \\
\mathrm{A}=20-25 \text { years old }\end{array}$ & 2 days & \\
\hline Steinberg et al. ${ }^{18}$ & $\mathrm{RCT}$ & $3 / 5$ & $\begin{array}{l}\mathrm{N}=80\left(390^{x} \text { and } 41 \text { \% }\right) \\
\mathrm{A}=24.87 \pm 4.14 \text { years old }\end{array}$ & 4 days & \\
\hline Christiansen et al..$^{19}$ & $\mathrm{RCT}$ & $2 / 5$ & $\begin{array}{l}N=24\left(24 \sigma^{\top}\right) \\
A=24 \pm 4 \text { years old }\end{array}$ & $\begin{array}{l}6 \text { weeks } \\
3 \text { sessions/week }\end{array}$ & \\
\hline Bo et al. ${ }^{20}$ & NCT & $0 / 5$ & $\begin{array}{l}\mathrm{N}=27\left(10 \sigma^{\pi} \text { and } 17 \%\right) \\
A=18-34 \text { years old }\end{array}$ & 2 days & 10 days \\
\hline Kidgell et al. ${ }^{21}$ & CCT & $2 / 5$ & $\begin{array}{l}\mathrm{N}=14\left(80^{x} \text { and } 6 \%\right) \\
\mathrm{A}=22.6 \pm 6.6 \text { years old }\end{array}$ & 3 days & 1 week for different tasks \\
\hline Krishnan et al. ${ }^{22}$ & $\mathrm{RCT}$ & $1 / 5$ & $\begin{array}{l}N=20 \\
A=22.8 \pm 5.8 \text { years old }\end{array}$ & 1 day & \\
\hline Krishnan et al..$^{23}$ & $\mathrm{RCT}$ & $1 / 5$ & $\begin{array}{l}\mathrm{N}=44\left(180^{\pi} \text { and } 26 \%\right) \\
\mathrm{A}= \\
\mathrm{EG} 1: 67.2 \pm 4.1 \text { years old } \\
\mathrm{EG} 2: 24.8 \pm 6.9 \text { years old }\end{array}$ & 2 days & \\
\hline Yen et al. ${ }^{24}$ & $\mathrm{RCT}$ & $1 / 5$ & $\begin{array}{l}\mathrm{N}=20\left(7 \circ^{\pi} \text { and } 13 \%\right) \\
\mathrm{A}= \\
\mathrm{EG} 1: 24 \pm 4.4 \text { years old } \\
\text { EG2 } 22.2 \pm 0.4 \text { years old }\end{array}$ & 1 day & \\
\hline Leung et al. ${ }^{3}$ & $\mathrm{RCT}$ & $1 / 5$ & $\begin{array}{l}\mathrm{N}=43\left(210^{x} \text { and } 22 \%\right) \\
\mathrm{A}=26.4 \pm 6.9 \text { years old }\end{array}$ & $\begin{array}{l}4 \text { weeks } \\
3 \text { sessions/week }\end{array}$ & 2 weeks \\
\hline Neva et al. ${ }^{25}$ & CCT & $1 / 5$ & $\begin{array}{l}N=17 \\
A=24 \pm 3 \text { years old }\end{array}$ & 4 days & 2 weeks \\
\hline Krishnan ${ }^{26}$ & $\mathrm{RCT}$ & $1 / 5$ & $\begin{array}{l}\mathrm{N}=45\left(25 \sigma^{x} \text { and } 20 \%\right) \\
\mathrm{A}=22.3 \pm 5.7 \text { years old }\end{array}$ & $1-2$ days (according to $E G$ ) & \\
\hline Witkowski et al. ${ }^{27}$ & RCT & $1 / 5$ & $\begin{array}{l}\mathrm{N}=32\left(160^{\pi} \text { and } 16 \%\right) \\
\mathrm{A}=14-20 \text { years old }\end{array}$ & 10 weeks & \\
\hline Wang et al..$^{28}$ & $\mathrm{RCT}$ & $1 / 5$ & $\begin{array}{l}\mathrm{N}=24\left(160^{x} \text { and } 8 \%\right) \\
\mathrm{EG} 1: 27.3 \pm 4.4 \text { years old } \\
\mathrm{EG} 2: 20.7 \pm 3.8 \text { years old }\end{array}$ & 1 day & \\
\hline Beg et al. ${ }^{29}$ & $\mathrm{RCT}$ & $3 / 5$ & $\begin{array}{l}\mathrm{N}=50\left(20 \sigma^{x} \text { and } 30 \text { \% }\right) \\
\mathrm{A}=23.4 \pm 2.5 \text { years old }\end{array}$ & $\begin{array}{l}4 \text { weeks } \\
2 \text { sessions/week }\end{array}$ & \\
\hline Brocken et al. ${ }^{30}$ & СCT & $2 / 5$ & $\begin{array}{l}\mathrm{N}=68(68 \%) \\
\mathrm{A}=9.5-12.5 \text { years old }\end{array}$ & $\begin{array}{l}7 \text { weeks } \\
14 \text { sessions }\end{array}$ & \\
\hline
\end{tabular}

ơ: male; o⿱: female; A: age; RCT: randomised clinical trial; CCT: crossover clinical trial; NRCT: non-randomised clinical trial; NCT: non-controlled trial; N: sample. 
Table 2. Intervention and main results.

\begin{tabular}{|c|c|c|c|}
\hline & Intervention & Variables analysed & Main results \\
\hline Leung et al. ${ }^{13}$ & $\begin{array}{l}\text { 4 EG: CT vs STM vs STwM vs Control } \\
\text { CT: match the position of the elbow } \\
\text { with that shown on the screen. }\end{array}$ & $\begin{array}{l}\text { 1-RM and MVC } \\
\text { CSE, SLII }\end{array}$ & $\begin{array}{l}\text { CSE and SLII transfer }(p<0.001) \\
\text { SLII differences between EG: STM, CT }>\text { STwM, control }\end{array}$ \\
\hline Dickins et al. ${ }^{14}$ & $\begin{array}{l}2 \text { EG: old vs young } \\
2 \text { types of CT: } \\
\text { Ballistic thumb abduction } \\
\text { Finger-to-thumb opposition } \\
\text { sequences }\end{array}$ & $\begin{array}{l}\text { CSE } \\
\text { Peak velocity } \\
\text { correct sequences }\end{array}$ & $\begin{array}{l}\text { Young: better overall performance } \\
\text { Transfer in the } 2 \text { tasks }(p<0.001) \\
\text { Increase in CSE only in the simple task ( } p=0.001) \text { with no } \\
\text { differences between groups }(p>0.1) \text {. } \\
\text { No relationship between CSE and transfer }(p>0.1) \text {. }\end{array}$ \\
\hline Graziado et al. ${ }^{15}$ & $\begin{array}{l}2 \text { EG: old vs young } \\
\text { CT: tracking points by } \\
\text { electromyographic activity of the } \\
\text { abductor pollicis brevis, 3rd dorsal } \\
\text { interosseous. }\end{array}$ & $\begin{array}{l}\text { Euclidean cursor-centre } \\
\text { distance: } \\
-120 \text { ms after start } \\
\text { (distance) } \\
\text { - For } 1 \mathrm{~s} \text { on reaching the } \\
\text { objective (score) } \\
\end{array}$ & $\begin{array}{l}\text { Young: better overall performance } \\
\text { Significant transfer }(p<0.001) \\
\text { Differences between ages in the distance variable, } \\
\text { (significant only in the elderly: } p<0.001) \\
\text { Score transfer significant relationship with learning } \\
(p=0.016) \text {. }\end{array}$ \\
\hline Pan et al. ${ }^{16}$ & $\begin{array}{l}2 \text { EG: healthy and with PN. } \\
\text { CT: Point tracking on } \\
\text { screen with digital pen. }\end{array}$ & Initial direction error & $\begin{array}{l}\text { Significant transfer }(p<0.001) \text {, greater in } R L \text { than } L R \\
(p=0.003) \text {. } \\
\text { Less transfer in healthy }(p=0.01) \text {. } \\
\text { Non-symmetrical transfer in healthy; but symmetrical with } \\
\text { PN, RL Group greater after-effects }(p=0,045) \text {. }\end{array}$ \\
\hline Sainburg et al..$^{17}$ & $\begin{array}{l}2 \mathrm{EG}: \mathrm{RL} \text { vs } \mathrm{LR} \\
\mathrm{CT} \text { : Point tracking } \\
\text { using the index. }\end{array}$ & $\begin{array}{l}V_{\text {max }} \\
\text { Peak acceleration } \\
\text { Acceleration duration }\end{array}$ & $\begin{array}{l}\text { Non-symmetrical Vmax transfer }(p=0.855) \\
\text { Asymmetrical transfer of Peak acceleration (lower in } L R \text {, } \\
p=0.0059) \text { and of Acceleration duration (higher in } L R \text {, } \\
p=0.0059 \text { ) } \\
\text { No differences after contralateral practice }\end{array}$ \\
\hline Steinberg et al..$^{18}$ & $\begin{array}{l}2 \text { EG: mirror vs control } \\
2 \text { subgroups per EG: novices vs } \\
\text { experts } \\
2 \text { types of CT with basketball: } \\
\text { Stationary dribbling } \\
\text { Slalom dribbling }\end{array}$ & $\begin{array}{l}\text { Correct sequences } \\
\text { Dribbling error }\end{array}$ & $\begin{array}{l}\text { Significant transfer }(p<0.001) \text { with differences according to } \\
\text { EG and experience }(p<0.05) \\
\text { Only experts differences according to EG: }(p<0.01) \text {, better } \\
\text { with mirror } \\
\text { Differences in control groups, greater transfer in novices } \\
(p<0.05) \\
\text { No differences between groups with mirror }(p>0.05) \\
\text { Dribbling error transfer without differences }(p>0.05) \\
\text { Transfer in slalom: experts greater with mirror }(p<0.05) \text {; } \\
\text { novices no transfer with mirror }(p>0.05)\end{array}$ \\
\hline Christiansen et al. ${ }^{19}$ & $\begin{array}{l}2 \text { EG: progressive difficulty vs no } \\
\text { progression } \\
\text { CT: a game called "BreakOut" contro- } \\
\text { lled by abduction and adduction of } \\
\text { the } 5 \text { th digit. }\end{array}$ & $\begin{array}{l}\text { CSE } \\
\text { "BreakOut" score }\end{array}$ & $\begin{array}{l}\text { Transfer only in progressive EG }(p<0.001) \\
\text { Increase in initial CSE without differences }(p<0.05) \\
\text { Increase in final CSE only in progressive EG } \\
\text { No relationship between CSE and transfer }(p>0.05) \text {. }\end{array}$ \\
\hline Bo et al. ${ }^{20}$ & $\begin{array}{l}1 \text { EG: with and without motor } \\
\text { disability } \\
\text { CT: Point tracking with handheld } \\
\text { joystick. }\end{array}$ & $\begin{array}{l}\text { DE } \\
\text { MT } \\
\text { Root mean square error }\end{array}$ & $\begin{array}{l}\text { Transfer not related to ADC score }(p>0.05) \\
D E \text { transfer }(p<0.05) \text { in normal feedback and MT transfer } \\
(p<0.05) \text { in enhanced feedback. } \\
\text { Transfer regardless of feedback ( } p>0.05) \\
\text { Relationship between learning and transfer: DE }(p<0.02) \text { in } \\
\text { normal feedback, MT }(p<0.04) \text { in enhanced feedback. }\end{array}$ \\
\hline Kidgell et al..$^{21}$ & $\begin{array}{l}3 \text { EG divided into } 3 \mathrm{CT} \text { : } \\
\text { "O'Connor dexterity" } \\
\text { "Purdue pegboard" } \\
\text { "Mirror Purdue pegboard" }\end{array}$ & Time to perform the task & $\begin{array}{l}\text { Greater transfer in Mirror Purdue }(p<0.05) \text {. } \\
\text { Relationship between learning and transfer in Mirror } \\
\text { Purdue }(p=0.03)\end{array}$ \\
\hline Krishnan et al. ${ }^{22}$ & $\begin{array}{l}2 \mathrm{EG}: \mathrm{RL} \text { vs } \mathrm{LR} \\
\mathrm{CT} \text { : Adjust gait pattern to the one } \\
\text { indicated in real time on the screen. }\end{array}$ & Tracking error & $\begin{array}{l}\text { Significant transfer }(p<0.003) \\
\text { No significant differences between sides }(p=0.247) \\
\text { Relationship between learning and transfer: } 84 \%(p<0.001)\end{array}$ \\
\hline Krishnan et al. ${ }^{23}$ & $\begin{array}{l}2 \mathrm{EG} \text { : old vs young } \\
\mathrm{CT} \text { : Adjust gait pattern to the one } \\
\text { indicated in real time on the screen. }\end{array}$ & Tracking error & $\begin{array}{l}\text { Young: better performance } \\
\text { Less transfer in the elderly }(p<0.05) \text { but without } \\
\text { differences in test without visual feedback }(p>0.1) \\
\text { Relationship between learning and transfer }(p>0.001) \text { : } \\
79 \% \text { young; } 56 \% \text { elderly }\end{array}$ \\
\hline
\end{tabular}


Table 2. Intervention and main results (continuation).

\begin{tabular}{|c|c|c|c|}
\hline & Intervention & Variables analysed & Main results \\
\hline Yen et al. ${ }^{24}$ & $\begin{array}{l}2 \text { EG: RL vs LR } \\
\text { CT: Point tracking using isometric } \\
\text { force of the ankle }\end{array}$ & $\begin{array}{l}\text { MT } \\
\text { Accuracy }\end{array}$ & $\begin{array}{l}\text { Significant transfer }(p<0.01) \\
\text { No differences between sides }(p=0.05)\end{array}$ \\
\hline Leung et al. ${ }^{3}$ & $\begin{array}{l}4 \text { EG: CT vs STM vs STwM vs Control } \\
\text { CT: match the position of the elbow } \\
\text { with that shown on the screen. }\end{array}$ & $\begin{array}{l}\text { 1-RM and MVC } \\
\text { CSE, SLII } \\
\text { MT }\end{array}$ & $\begin{array}{l}\text { Greater skill transfer in the CT group (GROUP x TIME: } \\
p=0.005) \text { but non-significant relationship between } \\
\text { learning and transfer ( } p>0.05) \text {. } \\
\text { Specific transfer similar between EG ( } p>0.05 \text { ). } \\
\text { Greater CSE and SLII improvements in CT and STM } \\
\text { No relationship SLII or CSE and transfer }(p>0.05) \text {. }\end{array}$ \\
\hline Neva et al..$^{25}$ & $\begin{array}{l}2 \text { EG: Previous aerobic warm-up* vs } \\
\text { Control } \\
\text { CT: Point tracking with handheld } \\
\text { joystick. }\end{array}$ & $\begin{array}{l}\text { Maximum side shift } \\
\text { Angle at peak velocity } \\
\text { Response time and MT }\end{array}$ & $\begin{array}{l}\text { Differences between groups during the intervention which } \\
\text { were no longer significant by the end }(p>0.05) \text {. } \\
\text { Significant transfer }(p<0.05) \\
\text { Differences between groups in reaction time }(p=0.045) \\
\text { which disappear in retention ( } p>0.05) \text {. }\end{array}$ \\
\hline Krishnan ${ }^{26}$ & $\begin{array}{l}2 \text { EG: massed practice vs distributed } \\
\text { practice } \\
\text { CT: Adjust gait pattern to the one } \\
\text { indicated in real time on the screen. }\end{array}$ & Tracking error & $\begin{array}{l}\text { Greater transfer in distributed practice }(p<0.044) \text {. } \\
\text { Significant relationship }(p<0.001) \text { between learning and } \\
\text { transfer }(76 \%) .\end{array}$ \\
\hline Witkowski et al. ${ }^{27}$ & $\begin{array}{l}2 \text { EG: CT vs Control } \\
\text { Intervention in } 3 \text { phases: } \\
\text { Whole-body, eye-to-hand and eye- } \\
\text { to-foot, specific to fencing }\end{array}$ & $\begin{array}{l}\text { Hand-grip strength } \\
\text { Accuracy of hits in } 3 \\
\text { different tests }\end{array}$ & $\begin{array}{l}\text { No significant differences in strength }(p=0.05) \\
\text { Significant improvement in } 3 / 3(p<0.001) \\
\text { Significant transfer in } 2 / 3(p<0.001 \text { and } p<0.01)\end{array}$ \\
\hline Wang et al..$^{28}$ & $\begin{array}{l}2 \text { EG: Left-handed vs Right-handed } \\
2 \text { subgroups: LR vs RL } \\
\text { CT: "pegboard task" }\end{array}$ & Time to perform the task & $\begin{array}{l}\text { Significant improvement and transfer }(p<0.05) \text { except } \\
\text { right hand of the right-handed, no improvement or } \\
\text { transfer }(p>0.1) \\
\text { No relationship between learning and transfer }(p>0.1\end{array}$ \\
\hline Beg et al. ${ }^{29}$ & $\begin{array}{l}2 \text { EG: CT vs Control } \\
\text { CT:"pegboard task" }\end{array}$ & $\begin{array}{l}\text { Time to perform the task } \\
\text { JTT test }\end{array}$ & $\begin{array}{l}\text { Significant improvement and transfer in the task }(p<0.05) \\
\text { and in JTT }(p<0.05) \text { except in the writing and simulated } \\
\text { feeding subtests }\end{array}$ \\
\hline Brocken et al. ${ }^{30}$ & $\begin{array}{l}2 \text { EG: } \\
\text { EG A: CT, Control } \\
\text { EG B: Control, CT } \\
\text { CT: training with hockey stick (adap- } \\
\text { ted) with hands switched over }\end{array}$ & Time to perform the test & $\begin{array}{l}\text { Significant improvement and transfer }(p<0.016) \\
\text { EG B faster in pre-test }(p<0.001) \text {; but } E G \text { A greater general } \\
\text { improvement }(p=0.043) \text {. } \\
\text { Longer times in pre-test related to greater improvement } \\
p=0.04\end{array}$ \\
\hline
\end{tabular}

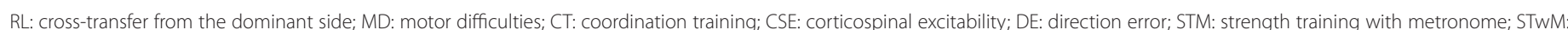

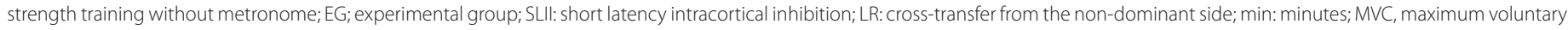
contraction; N: sample; RM: repetition maximum; MT: movement time. $V_{\max }$ : peak velocity.

Regarding the heterogeneity of objectives, we find that 3 papers compare transfer in young and old individuals $14,15,23,5$ analyse transfer according to the dominance of the trained limb, 2 studies analyse samples with pathology ${ }^{16,20}$, several studies compare interventions of varying difficulty or novelty $14,18,19,21,2$ compare transfer in visuomotor (VT) and strength (ST) training ${ }^{3,13}$, only 1 study centres on the influence of previous aerobic warm-up ${ }^{25}$, and another focuses on different distributions of practice ${ }^{26}$.

All the papers except Leung et al..$^{13}$ analyse performance. Electrophysiological measurements were taken in 4 studies $^{3,13,14,19}$. While all the studies analysed corticospinal excitability (CSE), only 2 analysed short latency intracortical inhibition (SLII) 3,13.

\section{Discussion}

\section{Influence of context on cross-transfer}

\section{Difficulty and novelty of the task and transfer}

Those papers which analyse the influence of difficulty show improved transfer when the task is challenging for the individual ${ }^{19,21}$. These results support the theoretical proposal whereby the type, novelty and complexity of the task condition transfer ${ }^{2}$. Greater demands for coordination and neuromuscular activation involve greater oxygenation $^{31}$ and cortical activation, favouring greater adaptations than simple tasks $\mathrm{do}^{32}$. 
Only Steinberg et al. ${ }^{18}$ analyse the influence of the novelty of the task on transfer, observing greater effects when the individual is a novice. The greater overall improvement of the novice group with direct feedback could be because the expert group is already at the most advanced stage of learning. At this stage, the sensorimotor map of the task is internalised, and sensory feedback and paying attention to execution are not necessary ${ }^{33}$, thereby decreasing the neuronal load and impairing transfer ${ }^{2}$. On the other hand, the benefit gained by the expert group when using the mirror could be because the tasks with normal feedback are considered simple and those viewed in reflection are considered complex. This consideration is described in Kidgell et al. ${ }^{21}$, where the task considered more complex is the one carried out through reflection in a mirror. This greater complexity forces the subject to focus their attention on both the reflection and execution of the task previously considered simple².

\section{Transfer differences according to age}

All the studies which include an elderly population find significant transfer ${ }^{14-16,23}$ despite showing lower performance than the younger group during the learning stage $\mathrm{e}^{14,15,23}$. However, there is no consensus regarding the differences between age groups.

When learning a new gait pattern, older subjects experience less transfer than younger subjects ${ }^{23}$. This is in line with studies which show decreased transfer in the elderly ${ }^{7,8}$ due to the mechanisms of neuronal degeneration associated with aging, such as the decrease in CSE $^{34}$ and the increase of intracortical inhibition ${ }^{35}$, which are both important in the consolidation of motor memory ${ }^{36}$. However, Dickins et al. ${ }^{14}$ and Graziado et al. ${ }^{15}$, with interventions focussing on upper limbs (UL), describe transfer as the same ${ }^{14}$ or even higher in the elderly ${ }^{15}$, which supports the HAROLD model; the aforementioned deficits are compensated by greater bilateral hemispheric recruitment ${ }^{9}$.

The greater transfer in the elderly for the variable measuring the feedforward component described by Graziado et al. ${ }^{15}$ could be due to several factors. While healthy elderly individuals conserve effective predictive adaptability, it remains unclear how this is affected by age ${ }^{37}$. However, findings suggest that the cognitive decline which occurs with age is responsible for the deterioration of predictive control ${ }^{38}$. So, cognitively healthy older individuals could improve and transfer this ability in a similar way to other age groups. On the other hand, the young people may not improve because the part of the task which evaluates anticipation does not pose a sufficient challenge, thereby decreasing transfer and generating a difference between groups. Finally, the lack of consensus on transfer in this population could be partly explained by methodological differences, which modify learning in the elderly population, and by individual characteristics, to which little attention is paid. Personal variables, such as lifestyle, could be protective factors against cognitive and memory decline.

\section{Transfer asymmetry}

The findings of the studies on this variable are relatively heterogeneous. While the 2 studies which analyse transfer in LL find that transfer occurs regardless of the trained side 22,24 , this factor does condition transfer in $U^{16,17,28}$.

In UL, it is observed that transfer from the dominant limb is greater and adapts better to different tests in the study by Pan et al. ${ }^{16}$. This concurs with the ideas advanced by the proficiency model (the dominant side is more effective when adapting to new tasks, transferring more and higher quality information) and hemispheric specialisation (the ability of each hemisphere to produce internal models of different skills) ${ }^{32}$. Specifically, the dominant side benefits from spatial skills ${ }^{39}$, as occurs in the paper by Pan et al. ${ }^{16}$, where a spatial control measurement is analysed. On the other hand, Sainburg et al. ${ }^{17}$ describe symmetrical transfer but with different adaptations according to the specific function of each hemisphere. This coincides with another study in which the transfer of ball shooting accuracy is symmetrical, but the motor strategies to reach this adaptation differ between sides ${ }^{40}$.

Finally, Wang et al. ${ }^{28}$ obtain an asymmetrical result in right-handers; their right hands do not improve or receive significant transfer, supporting the proficiency model. Left-handers, meanwhile, improve and receive transfer in both hands. This could be due to greater use by the left-handed of the non-dominant arm in their routines, favouring greater interhemispheric connectivity and dexterity with the non-dominant hand than in the right-handed ${ }^{41}$.

In the LL studies, symmetrical transfers of spatial control are observed in the gait study ${ }^{22}$ and in isometric control of the ankle ${ }^{24}$. The greater symmetry in LL could be explained by less lateralisation of these limbs compared to UL due to the different tasks and motor strategies that distinguish them ${ }^{42}$. Although certain studies concur in confirming LL symmetry ${ }^{6,43}$, the evidence which backs this idea is scarce, and there is little consensus on the matter, findings of asymmetry in certain variables also existing ${ }^{40,42}$.

Witkowski et al. ${ }^{27}$ and Brocken et al..$^{30}$ describe interventions in sports activities which involve equipment designed for use with the nondominant limb (fencing foil) and with hands switched over (hockey stick), respectively. Both studies observe significant transfer to the dominant side, demonstrating the ability to effectively transfer visuomotor skills from the non-dominant side in asymmetrical sports.

Finally, considering that contextual variables, such as the complexity and novelty of a task, influence the direction of transfer ${ }^{28}$, the heterogeneity of the intervention protocols hinders prediction of the symmetry pattern in transfer. This can be seen in Stöckel et al. ${ }^{6}$, where changing the instructions for the same task leads to variations in transfer from each limb depending on whether the subjects perceive the task as more spatial or more dynamic in nature.

\section{Transfer differences in participants with pathology}

The two papers which analyse this variable differ in terms of the pathology involved and, consequently, are not comparable. Nevertheless, they both find significant transfer comparable to that of the healthy group ${ }^{16,20}$.

In Pan et al. ${ }^{16}$, transfer is symmetrical in people with peripheral neuropathy. As this pathology involves degeneration of the soma- 
tosensory area ${ }^{44}$, the results explained previously could be due to compensatory neural mechanisms in a line similar to that proposed in the HAROLD model and cognitive decline ${ }^{16}$.

In Bo et al. ${ }^{20}$, transfer is similar between people with different motor abilities, suggesting that it is more related to the establishment of motor engrams than motor abilities. Finally, the difference in skill transferred according to feedback could be explained by the observations made in a contemporary study in which the movement time during the task increases as the feedback increases ${ }^{45}$. On this basis, the results of Bo et al. ${ }^{20}$ could be due to learning about the new condition, movement time improving after adaptation.

\section{Warm-up and practice distribution}

In the current literature, it has been observed that spacing out the intervention favours the learning of skills in UL in adults ${ }^{46}$. Despite the paucity of trials in this area with $L L$, the effect would appear to be the same ${ }^{47}$. In line with these studies, the transfer of a new gait pattern improves with distributed practice ${ }^{26}$.

Meanwhile, the temporary improvements in performance after warming up observed by Neva et al. ${ }^{25}$ differ from the findings of another study in which performance decreases after high intensity exercise ${ }^{48}$. This could be explained by a lower intensity of the warm-up, reducing fatigue when performing the test. On the other hand, temporary changes in reaction times may be due to acute increases in attention after exercise ${ }^{49}$, increases in attentional levels facilitating faster reaction times ${ }^{50}$.

\section{Scale of performance cross-transfer}

All the studies find significant performance improvements in both the trained and the contralateral limb in some of the variables studied $^{3,14-30}$. However, not all the papers indicate the percentage of contralateral improvement. Furthermore, the percentages described vary considerably across the different studies. This could be explained by the different variables analysed and interventions and protocols used in the different studies, leading to greater or lesser transfer and producing data which are not homogeneous.

\section{Scale of long-term transfer}

The only 5 studies which analyse long-term cross-transfer find significant transfer at the end of the intervention ${ }^{3,19,27,29,30}$. However, only 2 of them specify the transfer percentages ${ }^{3,19}$.

In Leung et al. $^{3}$, learning and transfer are greater in the group which specifically trains for the task. Although the specific transfer percentage is similar between ST groups (14.4 $\pm 3.8 \%$ to $11.9 \pm 4.5 \%$ in strength) and VT groups (12.4 $\pm 2.3 \%$ in motor control), the electrophysiological measurements depend on the type of intervention. So, although it is incorrect to say that ST and VT share the same corticospinal responses, they are somewhat similar. On comparing the magnitudes described by Leung et al. ${ }^{3}$ with similar intervention protocols, these are slightly higher than those described for strength transfer in UL (9.4\%) ${ }^{12}$. However,
Christiansen et al. ${ }^{19}$ describe much higher improvement percentages in their progressive training group $(76 \pm 14 \%)$. This could be due to the methodological differences between the two studies. On the one hand, Leung et a ${ }^{\beta}$ use a very different task to that of Christiansen et al. ${ }^{19}$ involving non-progressive difficulty adjustment and compare the results with the control group as Carrol et al..$^{51}$ suggest in order to reduce the influence of familiarisation with the test. Meanwhile, Christiansen et al. ${ }^{19}$ do not describe a washout period, their protocol is 2 weeks longer, the sample is smaller, there is no control group, and the variables which measure performance differ greatly between studies.

\section{Relationship between amount of learning and amount of transfer}

Most of the studies which analyse this variable, described as a percentage of contralateral improvement with respect to the amount of ipsilateral improvement, obtain significance. However, it is difficult to establish a consensus on this relationship because its magnitude is relatively variable according to the context, as observed in the other sections.

This relationship is significant in the $3 \mathrm{LL}$ studies. The percentages range from $84 \%{ }^{22}$ to $76 \%{ }^{26}$ and the result is lower in elderly individuals: $56 \%{ }^{23}$. However, all three studies are conducted by the same investigator, with very similar interventions and protocols. Furthermore, two of the studies analyse transfer by comparing the base measurement of the trained limb with the final measurement of the opposite limb, crossing data between limbs and biasing the result. In the UL studies by Bo et al. ${ }^{20}$ and Graziado et al. ${ }^{15}$, this relationship is only found in the variables with significant transfer and without differences between groups (homogeneous results). Finally, Kidgell et al. ${ }^{21}$ only find a correlation with learning in the most difficult task, while Leung et al. ${ }^{3}$ and Wang et al. ${ }^{28}$ find no relationship for VT. As occurs in Kidgell et al. ${ }^{21}$ with the easier tasks, the intervention used in Leung et al. ${ }^{3}$ may not be difficult enough to produce sufficient improvements to detect significance in the relationship. Similarly, the short duration of the study by Wang et al. ${ }^{28}, 4$ blocks of practice, may not permit detection of the relationship due to an insufficient amount of improvement.

\section{Electrophysiological measurements}

The 2 studies which compare VT and ST transfer find different cortical adaptations between groups. In Leung et al. ${ }^{13}$, there are only differences between groups for changes in SLII, but none for changes in CSE. However, in a later study, they report greater changes in CSE and SLII in VT and ST with metronome compared to the other groups ${ }^{3}$. This could be explained by the findings of Christiansen et al. ${ }^{19}$, where both groups initially have equal increases in CSE. However, these changes only last in the group in which the difficulty increases progressively. Thus, in the shorter study, VT and ST may generate the same excitatory changes because when a strength task is new to an individual, there is substantial motor control adaptation regardless of its complexity ${ }^{32}$. 
In Dickins et al. ${ }^{14}$, the CSE changes in the simple task but not the complex one could be because neural adaptation is not detected due to it occurring outside the primary motor cortex (M1). This can be explained based on the multiple cortical areas activated in the control of different parameters of the hand grip ${ }^{52}$ and on the fact that it is not possible to assume that the interactions between $\mathrm{M} 1$ are the origin of cross-facilitation just because the interaction of the two cortices is expressed through $\mathrm{M}^{2}$.

Finally, no significant relationship has been found between changes in $\mathrm{CSE}^{3,14,19}$ or SLII ${ }^{3}$ and improved task performance. This is consistent with Ruddy et al. ${ }^{2}$ when they affirm that cross-facilitation not only occurs in the homologues of the muscles involved in the task but also in the homologues of those which are not. Moreover, this activation lasts over time and is called "post-activation potentiation". Therefore it is wrong to assume that changes in excitability only represent significant adaptive changes.

\section{Conclusions}

The studies covered in this review show the presence of motor control transfer in visuomotor tasks in the short and long term. The magnitude and direction of this effect appears to be highly variable, depending on multiple contextual factors, such as state of the nervous system, hemispheric lateralisation and type of task. Similarly, the amount of learning appears to be related to the amount of transfer (albeit variably) but changes in CSE and SLII do not. On another note, the differences between UL and LL are inconclusive due to the limited number of studies reviewed. Finally, the low quality of the studies and general methodological heterogeneity make it difficult to draw firm conclusions from these findings.

It is necessary to conduct more studies of higher methodological quality and with more standardised measurement protocols, recording in more detail individual variables and aspects of the task which could influence transfer. Future trials should also study which factors modify the relationship between amount of learning and transfer to optimise the use of this tool.

\section{Conflict of interest}

The authors declare that they are not subject to any type of conflict of interest.

\section{Funding sources}

This research has not received any specific grant from agencies in the public, commercial or non-profit sectors.

\section{Bibliography}

1. Scripture E, Smith T, Brown E. On the education of muscular control and power. Studies from Yale Psycological Laboratory. 1894;114-9.

2. Ruddy K, Carson, R. Neural pathways mediating cross education of motor function. Front Hum Neurosci. 2013;7:397.
3. Leung M, Rantalainen T, Teo WP, Kidgell D. The ipsilateral corticospinal responses to cross-education are dependent upon the motor-training intervention. Exp Brain Res. 2018;236:1331-46

4. Wang J, Sainburg RL. Interlimb transfer of novel inertial dynamics is asymmetrical. $J$ Neurophysiol. 2004;92:349-60.

5. Criscimagna-Hemminger S, Donchin O, Gazzaniga M, Shadmehr R. Learned dynamics of reaching movements generalize from dominant to nondominant arm. J Neurophysiol. 2003:89:168-76.

6. Stöckel T, Wang J. Transfer of short-term motor learning across the lower limbs as a function of task conception and practice order. Brain and Cognition. 2011;77:271-9.

7. Hinder M, Carroll T, Summers J. Inter-limb transfer of ballistic motor skill following non-dominant limb training in young and older adults. Exp Brain Res. 2013;227:19-29.

8. Hinder M, Schmidt M, Garry M, Carroll T, Summers J. Absence of cross-limb transfe of performance gains following ballistic motor practice in older adults. J Appl Physiol. 2011;110:166-75

9. Cabeza R. Hemispheric asymmetry reduction in older adults: the HAROLD model Psychol Aging. 2002;17:85-100

10. Ehsani F, Nodehi-Moghadam A, Ghandali H, Ahmadizade Z. The comparison of crosseducation effect in young and elderly females from unilateral training of the elbow flexors. Med J Islam Repub Iran. 2014;28:138.

11. Wang J, Przybyla A, Wuebbenhorst K, Haaland K, Sainburg R. Aging reduces asymmetries in interlimb transfer of visuomotor adaptation. Exp Brain Res. 2011;210:283-90.

12. Manca A, Dragone, D, Dvir Z, Deriu F. Cross-education of muscular strength following unilateral resistance training: a meta-analysis. Eur J App/ Physiol. 2017;117:2335-54

13. Leung M, Rantalainen T, Teo W-P, Kidgell D. Motor cortex excitability is not differentially modulated following skill and strength training. Neurosci. 2015;305:99-108.

14. Dickins $D$, Sale M, Kamke M. Intermanual transfer and bilateral cortical plasticity is maintained in older adults after skilled motor training with simple and complex tasks. Front in Aging Neurosci. 2015;7:73.

15. Graziadio S, Nazarpour K, Gretenkord S, Jackson A, Eyre J. Greater intermanual transfer in the elderly suggests age-related bilateral motor cortex activation is compensatory. J Mot Behav. 2015;47:47-55.

16. Pan Z, Van Gemmert, A. Peripheral neuropathy reduces asymmetries in inter-limb transfer in a visuo-motor task. Laterality. 2016;21:255-66.

17. Sainburg R, Schaefer S, Yadav V. Lateralized motor control processes determine asymmetry of interlimb transfer. Neuroscience. 2016;334:26-38.

18. Steinberg F, Pixa N, Doppelmayr M. Mirror visual feedback training improves intermanual transfer in a sport-specific task: a comparison between different skill levels. Neural Plast. 2016:1-11.

19. Christiansen L, Larsen M, Grey M, Nielsen J, Lundbye-Jensen J. Long-term progressive motor skill training enhances corticospinal excitability for the ipsilateral hemisphere and motor performance of the untrained hand. Eur Journal of Neurosci. 2016;45:1490500 .

20. Bo J, Lee C. Inter-limb transfer of kinematic adaptation in individuals with moto difficulties. Neurosci Lett. 2017;654:63-9.

21. Kidgell D, Frazer A, Pearce A. The effect of task complexity influencing bilateral transfer. Int J Exerc Sci. 2017;10:1174-83.

22. Krishnan C, Ranganathan $\mathrm{R}$, Tetarbe $M$. Interlimb transfer of motor skill learning during walking: no evidence for asymmetric transfer. Gait Posture. 2017;56:24-30.

23. Krishnan C, Washabaugh E, Reid C, Althoen M, Ranganathan R. Learning new gait patterns: age-related differences in skill acquisition and interlimb transfer. Exp Gerontol. 2018;11::45-52

24. Yen S-C, Olsavsky L, Cloonan C, Llanos A, Dwyer K, Nabian M, et al. An examination of lower limb asymmetry in ankle isometric force control. Hum Mov Sci. 2018;57:40-9.

25. Neva J, Ma J, Orsholits D, Boisgontier M, Boyd L. The effects of acute exercise on visuomotor adaptation, learning, and inter-limb transfer. Exp Brain Res. 2019;237:1109-27.

26. Krishnan C. Learning and interlimb transfer of new gait patterns are facilitated by distributed practice across days. Gait Posture. 2019;70:84-9.

27. Witkowski M, Bojkowski L, Karpowicz K, Konieczny M, Bronikowski M, Tomczak M. Effectiveness and durability of transfer training in fencing. Int. J. Environ. Res. Public Health. 2020;17.

28. Wang YF, Zhao J, Negyesi J, Nagatomi R. Differences in the magnitude of motor skil acquisition and interlimb transfer between left- and right-handed subjects after shortterm unilateral motor skill practice. Tohoku J. Exp. Med. 2020;251:31-7.

29. Beg RA, Shaphe MA, Qasheesh M, Ahmad F, Anwer S, Alghadir AH. Intermanual transfer effects on performance gain following dominant hand training in community-dwelling healthy adults: a preliminary study. J Multidiscip Healthc. 2021;14:1007-16. 
30. Brocken JEA, van der Kamp J, Lenior M, Savelsbergh GJP. Using modified equipment in field hockey leads to positive transfer of learning effect. Front Psychol. 2021;12:653004.

31. Holper L, Biallas M, Wolf M. Task complexity relates to activation of cortical motor areas during uni-and bimanual performance: a functional NIRS study. Neuroimage. 2009;46:1105-13.

32. Farthing J. Cross-education of strength depends on limb dominance: implications for theory and application. Exerc Sport Sci Rev. 2009;37:179-87.

33. Halsband $U$, Lange R. Motor learning in man: a review of functional and clinical studies. J Physiol Paris. 2006;99:414-24.

34. Sale M, Semmler J. Age-related differences in corticospinal control during functional isometric contractions in left and right hands. J Appl Physiol. 2005;99:1483-93.

35. McGinley M, Hoffman R, Russ D, Thomas J, Clark B. Older adults exhibit more intracortical inhibition and less intracortical facilitation than young adults. Exp Gerontol. 2010;45:671-8

36. Robertson E, Takacs A. Exercising control over memory consolidation. Trends Cogn Sci. 2017;21:310-2.

37. Bohm S, Mademli L, Mersmann F, Arampatzis A. Predictive and reactive locomotor adaptability in healthy elderly: a systematic review and meta-analysis. Sports Med. 2015;45:1759-77.

38. Levy-Tzedek S. Changes in predictive task switching with age and with cognitive load. Front Aging Neurosci. 2017;9:375.

39. Sainburg R. Evidence for a dynamic-dominance hypothesis of handedness. Exp Brain Res. 2002;142:241-58.

40. King A, Wang Z. Asymmetrical stabilization and mobilization exploited during static single leg stance and goal directed kicking. Hum Mov Sci. 2017;54:182-90.

41. Serrien D, Sovijärvi-Spapé, M. Manual dexterity: functional lateralisation patterns and motor efficiency. Brain and cognition. 2016;108:42-6.
42. Morris T, Newby N, Wininger M, Craelius W. Inter-limb transfer of learned ankle movements. Exp Brain Res. 2009;192:33-42.

43. Van Hedel H, Biedermann M, Erni T, DietzV. Obstacle avoidance during human walking: transfer of motor skill from one leg to the other. J Physiol. 2002;543:709-17.

44. Selvarajah D, Wilkinson L, Fang F, Sankar A, Davies J, Boland E, et al. Structural and functional abnormalities of the primary somatosensory cortex in diabetic peripheral neuropathy: a multimodal mri study. Diabetes. 2019;68:796-806.

45. Ambron E, Schettino L, Coyle M, Jax S, Coslett H. When perception trips action! The increase in the perceived size of both hand and target matters in reaching and grasping movements. Acta Psychol. 2017;180:160-8.

46. Smith C, Scarf D. Spacing repetitions over long timescales: a review and a reconsolidation explanation. Front Psychol. 2017;8:962.

47. Shea C, Lai Q, Black C, Park J-H. Spacing practice sessions across days benefits the learning of motor skills. Hum Mov Sci. 2000;19:737-60.

48. Thomas R, Flindtgaard M, Skriver K, Geertsen S, Christiansen L, Korsgaard L, et al. Acute exercise and motor memory consolidation: does exercise type play a role? Scand J Med Sci Sports. 2016;27:1523-32

49. De Greeff J, Bosker R, Oosterlaan J, Visscher C, Hartman E. Effects of physical activity on executive functions, attention and academic performance in preadolescent children: a meta-analysis. J Sci Med Sport. 2018;21:501-7.

50. Posner M. Orienting of Attention: Then and Now. Q J Exp Psychol. 2016;69:1864-75.

51. Carroll T, Herbert R, Munn J, Lee M, Gandevia S. Contralateral effects of unilateral strength training: evidence and possible mechanisms. J Appl Physiol. 2006;101:1514-22.

52. Holmström L, de Manzano Ö, Vollmer B, Forsman L, Valero-Cuevas F, Ullén F, et al. Dissociation of brain areas associated with force production and stabilization during manipulation of unstable objects. Exp Brain Res. 2011;215:359-67. 